\title{
Chapter 6 \\ A Support Framework for the Migration of E-Government Services to the Cloud
}

\author{
Abílio Cardoso \\ Universidade Portucalense, Portugal \\ Fernando Moreira \\ Universidade Portucalense, Portugal \\ Paulo Simões \\ University of Coimbra, Portugal
}

\begin{abstract}
Public and federal agencies from countries around the world are increasingly providing information technology based services via the Internet - known as e-government. Several of the general requirements of e-government services are satisfactorily met by the emerging Cloud Computing paradigm that promises a number of benefits such as service elasticity (the ability to handle peaks and troughs of demands); optimization of costs; capacity to handle large volumes of data; and a generalized model of Internet-based access for end-users. For this reason, it is no surprise that Cloud related technologies are gradually leveraging e-government platforms. In this chapter, a support framework is outlined that complies with and extends the well-known ITIL (Information Technology Infrastructure Library) set of best practices for IT (Information Technology) service management. It is suggested that the proposed framework can be usefully deployed to assist in the process of migrating e-government services provision to the Cloud Computing environment.
\end{abstract}

\section{INTRODUCTION}

The coverage and quality of electronic government (e-government) public services that provide information technology- based services are currently the focus of systematic benchmarking studies, such as the European E-Government Benchmarking scheme (Tinholt, 2014) which issues reports that are regularly released by the European Commission. According to the 2014 edition of this Benchmark, governments

DOI: $10.4018 / 978-1-4666-8629-8 . c h 006$

Copyright $\odot$ 2016, IGI Global. Copying or distributing in print or electronic forms without written permission of IGI Global is prohibited. 


\section{A Support Framework for the Migration of E-Government Services to the Cloud}

are aware of the importance of making their online services user-oriented and user-friendly. However, there remains a concern on how to make the services readily available around the clock and there is ample room for improvement in this area.

While the potential economic and social benefits of the e-government concept are evident and widely recognized, in the implementation of each specific e-government service, there is still a good deal of scope for efficiency gains, cost reductions, process optimization and other improvements. This means political and technical decision- makers must take into account a large number of technical and nontechnical factors when designing new services (or new sets of services), so that they can maximize the benefits for government services and society as a whole.

On the other hand, pressure is increasing on Information Technology (IT) personnel to carry out more (and better) activities with fewer resources. This pressure to rationalize IT costs has led to a number of paradigms, new technologies and buzzwords. Some of them have failed to fulfil their promises, while others have become successfully embedded in IT practices and infrastructures, and provided considerable benefits. The paradigm of Cloud Computing (CC) is currently riding this wave, and promises to be the next great revolution in IT.

Several of the general requirements of e-government services seem to directly match the advantages offered by the CC: the benefits such as service elasticity (the ability to handle peaks and troughs of demand); optimization of costs; the capacity to handle large volumes of data; complex but loosely coupled interdependence between services and database systems; and general Internet-based access for end-users. For this reason, it is no surprise that CC concepts are gradually leveraging e-government platforms, in some cases limited to private clouds - because of security and privacy concerns - and in other cases supported by public and hybrid clouds.

The remaining sections of this chapter are structured as follows. The next section provides a brief overview of CC, its related concepts, ITIL and its relationship with e-government. The following section outlines the framework that underpins the process of migrating e-government services, applications, data and infrastructures to CC. There is then a discussion on how the framework can be used in the context of e-government, and provides specific examples. The penultimate section presents a practical example of the use of the framework. The final section presents the conclusions and makes recommendations for future work.

\section{Cloud Computing and ITIL: An Overview}

In the last few decades, the pressure to rationalize IT costs has led to a number of new paradigms, technologies and buzzwords. Some of these have failed to fulfil their promises, while others have become successfully embedded in IT practices and infrastructures, and provided considerable benefits. The CC paradigm is currently riding this wave, and becoming the next great revolution in IT. CC appears to have the right technological and market features to ensure it becomes widely successful. ITIL (Information Technology Infrastructure Library) is a de facto standard and the reference model for IT management (Axelos, 2013). It consists of a set of good practices that must be followed in the operation and maintenance of IT. This model was developed by the UK government for use in the IT companies, and was quickly adopted throughout Europe as the standard for best practices in IT service delivery. 
37 more pages are available in the full version of this document, which may be purchased using the "Add to Cart" button on the product's webpage: www.igi-global.com/chapter/a-support-framework-for-the-migration-of-egovernment-services-to-the-cloud/136876? camid=4v1

This title is available in Advances in Electronic Government, Digital Divide, and Regional Development, InfoSci-Books, Business, Administration, and Management, InfoSci-Government Science and Technology. Recommend this product to your librarian: www.igi-global.com/e-resources/library-recommendation/?id=86

\section{Related Content}

Organizational Control Related to Cloud

Sathish A. Kumar (2015). Cloud Technology: Concepts, Methodologies, Tools, and Applications (pp. 17981809).

www.igi-global.com/chapter/organizational-control-related-to-cloud/119933?camid=4v1a

Grids, Clouds, and Massive Simulations

Levente Hajdu, Jérôme Lauret and Radomir A. Mihajlovi (2014). Handbook of Research on High

Performance and Cloud Computing in Scientific Research and Education (pp. 308-340).

www.igi-global.com/chapter/grids-clouds-and-massive-simulations $/ 102416$ ?camid=4v1a

Analysis of Cloud Services on Business Processes in the Digitalization of the Consumer Product Industry

Ute Riemann (2015). Delivery and Adoption of Cloud Computing Services in Contemporary Organizations (pp. 129-165).

www.igi-global.com/chapter/analysis-of-cloud-services-on-business-processes-in-the-

digitalization-of-the-consumer-product-industry/126852?camid=4v1a

Organizational and Management Aspects of Cloud Computing Application in Scientific Research Mladen udanov and Jovan Krivokapi (2015). Cloud Technology: Concepts, Methodologies, Tools, and Applications (pp. 1852-1876).

www.igi-global.com/chapter/organizational-and-management-aspects-of-cloud-computingapplication-in-scientific-research/119936?camid=4v1a 